\title{
Местные финансы в новой ситуации
}

В.В. ЛЕВИНА, доктор экономических наук, Тульский государственный университет, Тула

Анализируются современное состояние правовой базы и практики формирования и использования бюджетных средств на местном уровне. По мнению автора, в России потенциал местных финансов задействован далеко не в полном объеме, что обусловлено наличием устойчивых стереотипов в области муниципальной бюджетной политики, связанных с повышением уровня прозрачности бюджетов, стабильностью бюджетных доходов, использованием программноцелевого бюджетирования, а также финансовых механизмов вовлечения граждан в решение вопросов местного значения. Для того, чтобы выяснить, насколько действенно использование указанных бюджетных механизмов, выявить не всегда очевидные последствия усовершенствований в области бюджетного процесса, автор анализирует реальное положение дел в области местных финансов, акцентируя внимание на изменениях в муниципальной бюджетной политике последних лет.

Ключевые слова: муниципальные финансы, бюджетная политика, программно-целевое бюджетирование, бюджетные доходы, межбюджетные трансферты

Проводимые на протяжении последних 25 лет в России кардинальные и масштабные преобразования во всех сферах жизнедеятельности государства и общества существенно, но непоследовательно трансформировали принципиальные основы местных финансов. Происходившие в этой сфере изменения в 1990-х гг. характеризовались стихийным ростом региональной самостоятельности и неупорядоченной децентрализацией. Затем в 2000-е гг, когда произошло восстановление доминирующего значения государства, в области муниципальных финансов сформировалась иллюзорная стабильность, которая, однако, характеризовалась устойчивым недостатком налоговых и неналоговых поступлений, преобладанием трансфертов среди бюджетных доходов, несамостоятельностью местных властей при принятии финансовых решений. Такая ситуация была следствием увеличения объемов перераспределения финансовых ресурсов через федеральный бюджет, унификации бюджетного законодательства. Незначительная роль местных финансов стала естественным следствием субординации и регламентации в системе отношений «государство-регионы-муниципалитеты». 
В последние годы большие надежды возлагались на увеличение объемов целевых межбюджетных трансфертов как предпосылку роста эффективности бюджетной политики региональных и местных властей. Предполагалось и некоторое увеличение уровня финансовой самостоятельности органов местного самоуправления для повышения результативности решения вопросов местного значения [Силуанов, 2014]. В современных условиях очевидным становится, что потенциал местных бюджетов как важного звена публичных финансов используется далеко не в полной мере [Леонов, 2017]. Для преодоления сложившейся ситуации представляется важным проанализировать состояние правовой базы и практики в области местных финансов, выявить неочевидные последствия внедрения бюджетных новаций.

\section{Программно-целевое бюджетирование на местном уровне: рост эффективности или увеличение объема документов?}

Основными документами, регулирующими функционирование и трансформацию местных финансов, являются Бюджетный кодекс РФ (БК РФ) и федеральный закон № 131 «Об общих принципах организации местного самоуправления в Российской Федерации» (Ф3-131). БК РФ регулирует непосредственно технику формирования и использования бюджетных средств, а Ф3-131 предопределяет «рамки» бюджетной политики, регулируя сущностные и организационные вопросы местного самоуправления, а также задачи, полномочия и возможности местных властей.

Изменения в бюджетной политике, происходившие в последние десять лет, в значительной мере были связаны с внедрением бюджетирования, ориентированного на результат, расширением использования стратегического планирования в финансовой сфере, наращиванием объемов целевых межбюджетных трансфертов. Правовое и методологическое регулирование данного процесса проявлялось в изменениях, вносимых в бюджетное законодательство, а также в разработке Минфином России объемных методических рекомендаций территориальным властям по соответствующей тематике. Так, в 2014 г. были разработаны «Методические рекомендации по составлению и исполнению бюджетов субъектов РФ и местных бюджетов на основе государственных муниципальных программ», которые нацелены 
на переход к составлению территориальных бюджетов преимущественно по программно-целевому принципу.

В 2015 г. Минфин России выпустил «Методические рекомендации органам государственной власти субъектов РФ по долгосрочному бюджетному планированию», ориентированные в том числе на местный уровень управления. Документ детализирует требования статьи 170.1 БК РФ «Долгосрочное бюджетное планирование» и предполагает количественную оценку бюджетных рисков, составление бюджетного прогноза территории в нескольких вариантах в зависимости от сценарных условий, а также планирование бюджетных параметров на основе прогноза социально-экономического развития каждые три года (для муниципальных образований - на шесть и более лет, для субъектов Федерации - на 12 лет). Однако если региональные власти обязаны разрабатывать подобные документы, то на муниципальном уровне решение о формировании прогноза принимает представительный орган муниципалитета. Очевидно, что для большинства регионов составление подобных прогнозов стало преимущественно формальной задачей, которая решается путем формирования очередного приложения к закону (решению) о бюджете на соответствующий период.

Названные инициативы в области бюджетного процесса, ориентированные на решение безусловно важных и значимых задач, и часто скрупулезно исполняемые на формальном уровне, к сожалению, далеко не всегда приводят к ожидаемым результатам. На наш взгляд, это обусловлено устойчивостью сложившихся неформальных институтов.

Согласно теории институциональных изменений Д. Норта, неформальные институты (правила, процедуры, кодексы поведения и т.д.) являются гораздо более стабильными и менее подверженными изменениям, чем формальные правила и законы, причем независимо от их эффективности [Норт, 1997]. Думается, что в сфере реформирования бюджетного процесса на местном уровне как раз и возникла подобная ситуация.

Уровень требований к составлению бюджетной документации растет, как и сложность и объем самих документов. Местные власти, следуя «букве закона», вынуждены формировать бюджетные прогнозы, планы, программные бюджеты, часто не понимая их сути и не видя в этом практической пользы. Иногда 
формальное исполнение различных требований и рекомендаций стимулируется дополнительными трансфертами из региональных бюджетов (например, в рамках реформирования территориальных финансов или стимулирования лучших практик), что подкрепляет заинтересованность местных властей во внедрении бюджетных новаций. Но даже материальная заинтересованность, приводящая к более быстрому их внедрению, крайне редко затрагивает суть реализации бюджетного процесса.

Все более сложное и формализованное бюджетирование на муниципальном уровне не приводит к изменению реальной ситуации: не наблюдается повсеместного существенного роста удовлетворенности граждан качеством и доступностью бюджетных услуг, темпы роста налоговых и неналоговых доходов на местах все еще отстают от инфляции. Все это позволяет утверждать, что формальное повышение качества бюджетного процесса на местном уровне не может быть самоцелью финансовой политики.

\section{Доступная для граждан форма бюджета или поле для агентских конфликтов?}

Уровень сложности бюджетной документации муниципального образования, составленной в соответствии с современными нормативными требованиями, настолько возрос, что это стало противоречить государственному курсу на «информационную открытость».

В целях повышения качества бюджетного процесса и открытости данных в сентябре 2015 г. Минфином РФ были утверждены «Методические рекомендации по представлению бюджетов субъектов РФ и местных бюджетов... в доступной для граждан форме». То есть отныне помимо решения о бюджете, составляемого в соответствии с требованиями бюджетной классификации, готовится дополнительный упрощенный и иллюстрированный документ, основанный на тех же исходных данных [Жукова и др., 2015].

Взаимодействие более информированных представителей местных властей и нуждающихся в информации жителей, которые являются конечными потребителями бюджетных услуг, избирателями и налогоплательщиками, может рассматриваться как взаимоотношения «принципал-агент» в рамках теории 
агентских отношений (agency theory) [Дженсен, Меклинг, 2004]. Значимым моментом в формировании и реализации таких отношений является асимметричность информации. В рассматриваемом случае ее уровень довольно существен, поскольку у большинства жителей отсутствует профессиональное образование в области финансов и права, не говоря уже об опыте составления и «чтения» бюджетной документации.

Необходимость составления упрощенных «бюджетов для граждан» создает возможности для определенного манипулирования данными и возникновения на этой почве «агентских конфликтов», когда, например, в презентационных материалах подчеркиваются те моменты, в которых наблюдаются положительные изменения и «замалчиваются» отрицательные. И хотя информационная асимметрия неизбежна на всех уровнях управления, однако именно на муниципальном «проблема принципала-агента» проявляется наиболее ярко, так как взаимодействие граждан и местных властей в наибольшей степени соответствует отношениям менеджеров и акционеров внутри корпорации (которые, собственно, и рассматриваются классической теорией агентских отношений). На местном уровне не только власти более «доступны» и ближе к народу, но и решаемые ими «локальные» проблемы сильнее затрагивают конкретные нужды и интересы населения.

На наш взгляд, гораздо более перспективным, нежели составление отдельных «бюджетов для граждан», видится представление необходимых для понимания реальной финансовой ситуации в муниципальном образовании данных непосредственно в Решении о бюджете (в основном тексте и ключевых приложениях). Это предполагает, в частности, упрощение формальных требований к составлению бюджетов местного уровня.

\section{Стабильность параметров местных бюджетов: устойчивость или отсутствие роста доходов?}

Централизация управления, реализуемого в рамках принятой в современной России патерналистской модели, находит свое естественное продолжение в бюджетно-финансовой сфере. Сформированная система распределения бюджетных доходов и расходных полномочий предполагает перетоки между уровнями управления значительного объема бюджетных средств, так как многие субъекты Федерации и большинство муниципальных образований 
не могут обеспечить реализацию своих полномочий за счет собственных налоговых и неналоговых поступлений [Леонов, 2016].

Практика показывает, что уровень трансфертов в общем объеме доходов местных бюджетов в среднем по муниципальным образованиям всех типов в последние годы сохраняется на уровне $60 \%$. Примечательно, что общая структура доходов местных бюджетов оказалась малочувствительна к изменениям финансовой ситуации: среднее соотношение суммы налоговых и неналоговых поступлений и трансфертов практически не менялось как в кризисные для российской экономики годы, так и в периоды некоторого улучшения финансово-экономической ситуации (рис. 1). По нашему мнению, это связано с предопределенной БК РФ высокой зависимостью местных бюджетов от трансфертных поступлений и невозможностью для большинства муниципальных образований существенного роста самофинансирования в условиях сложившихся «правил игры».

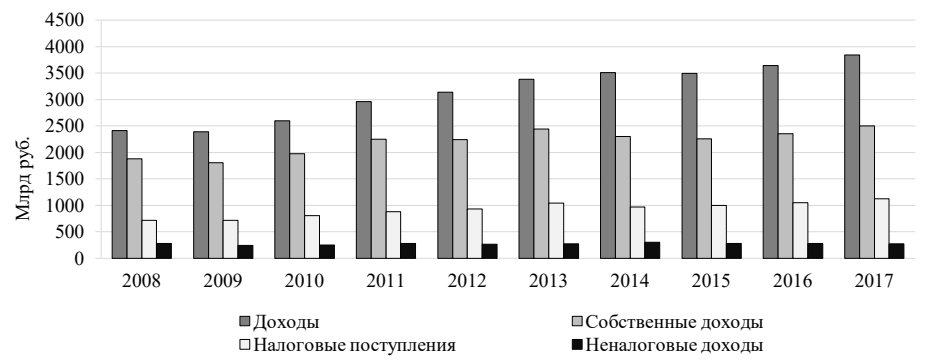

Источник рис. 1-3: составлено автором по данным ежегодных отчетов по мониторингу местных бюдежтов, представленных на официальном сайте Минфина России.

Puc. 1. Доходы местных бюджетов в 2008-2017 гг.

Другой характерной тенденцией является устойчивый рост превышения доходов над собственными доходами, то есть постоянный рост объема субвенций, связанный с расширением практики делегирования полномочий с регионального на местный уровень. С нашей точки зрения, это вряд ли можно рассматривать как положительное изменение в области муниципальной бюджетной политики.

Одновременно в рассматриваемом периоде возрастал объем муниципального долга, что является очевидным индикатором 
ухудшения ситуации для муниципальных финансов в целом. С 2009 г. по 2017 г. данный показатель вырос почти в три раза и сегодня составляет около четверти всех налоговых доходов местных бюджетов. В то же время собственные доходы за тот же период увеличились всего на $30 \%$.

Рассмотрим более подробно основные тенденции в области формирования налоговых и неналоговых доходов и трансфертных поступлений местных бюджетов.

\section{Налоговые доходы местных бюджетов: особенности и проблемы}

Основу налоговых доходов местных бюджетов на протяжении всего периода составлял НДФЛ (рис. 2). Наиболее значимым фактором, определяющим объем поступлений по этому налогу и в целом структуру налоговых доходов муниципальных образований, является вовсе не размер заработной платы местных жителей, а изменение норматива зачисления НДФЛ, определяющего «долю» налога, остающуюся в распоряжении муниципалитета. В зависимости от изменений величины норматива, в местных бюджетах существенно меняется объем поступлений, что прекрасно видно на рисунке. Изначально величина норматива составляла 10\%, затем в 2012 г. была увеличена до 20\%, а в 2014-м снижена до 15\%.

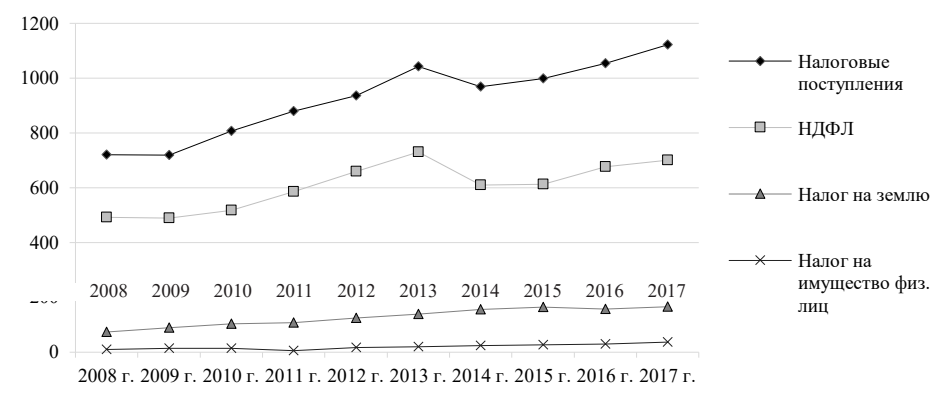

Puc. 2. Налоговые доходы местных бюджетов в 2008-2017 гг., млрд руб.

На графике отчетливо видна тенденция роста поступлений налога на имущество физических лиц: с 2008 г. по 2017 г. они увеличились в четыре раза, что в значительной мере связано с переходом к оценке имущества по кадастровой стоимости. 
Однако в структуре местных бюджетов эти поступления не играют существенной роли, в 2017 г. они составили лишь около $3 \%$ от общего объема налоговых доходов. Гораздо более значим для муниципалитетов налог на землю, особенно это касается сельских поселений. В период с 2008 по 2017 гг. поступления земельного налога выросли более чем вдвое, и по итогам 2017 г. составили в целом по РФ свыше 160 млрд руб., или около $15 \%$ от общего объема налоговых доходов местных бюджетов.

Таким образом, основной налоговый источник местных бюджетов (НДФЛ) не является местным налогом. Объем поступлений по нему никак не связан с усилиями местных властей по наращиванию налоговой базы (рост оплаты труда, увеличение количества рабочих мест). По двум оставшимся налогам, формирующим местные бюджеты, сохраняется проблема федеральных льгот. В частности, существенная часть земель не выступает в роли объекта налогообложения, другие - освобождены от уплаты налога на землю, что неизбежно сужает налоговую базу. В целом возможности местных властей в наращивании налоговых доходов невелики и не сравнимы с последствиями решений в этой сфере, принимаемых на вышестоящем уровне, что способствует сохранению значительной трансфертной зависимости местных бюджетов.

\section{Самообложение и инициативное бюджетирование: современные практики или возврат к архаичным формам финансового взаимодействия?}

Особым видом неналоговых доходов являются средства самообложения граждан, то есть разовые платежи, осуществляемые для решения конкретных вопросов местного значения, получившие распространение в последнее время в некоторых регионах. Несмотря на небольшие объемы средств, данный источник интересен как способ вовлечения граждан в решение вопросов, их участие в развитии инфраструктуры локальных сообществ. По данным Минфина России, в 2016 г. практика самообложения применялась в 1,5 тыс. муниципальных образований (преимущественно сельских) в 35 регионах. Объем дополнительных средств, полученных местными бюджетами 
в 2016 г., составил 213,6 млн руб., это более чем в восемь раз превышает показатели 2013 г.

О том, что властные органы высоко оценили перспективность механизма самообложения, свидетельствует внесение в действующее законодательство изменений, предполагающих возможность его применения в отношении не только муниципального образования в целом, как это было ранее, но и конкретного населенного пункта, входящего в состав поселения или внутригородского района.

Наибольший объем поступлений от самообложения в последние годы приходится на Республику Татарстан (более 70\% от общего объема средств), где практикуется софинансирование этих инициатив из регионального бюджета. Однако у автора сложилось неоднозначное мнение по поводу практики распределения бюджетных трансфертов в целях стимулирования самообложения граждан. Положительно оценивается то обстоятельство, что в результате у муниципалитета появляется дополнительный источник дохода, который он может направить на решение неотложных нужд местных жителей. Однако по своей сути механизм самообложения граждан должен быть инициирован «снизу», так как именно жители должны быть заинтересованы в финансировании тех или иных расходов за счет собранных средств. В том случае, когда самообложение «премируется», возникает вероятность, что и сама инициатива, и конечное решение о финансировании будут формироваться не на уровне муниципалитета, а «сверху».

Альтернативным способом привлечения средств граждан для решения конкретных проблем на местном уровне является инициативное бюджетирование [Вагин и др., 2015], которое только недавно вошло в российскую практику, но развивается достаточно активно. Так, в 2016 г. объем средств, направленных на реализацию проектов с использованием инициативного бюджетирования, в целом по регионам России вырос в три раза по сравнению с 2015 г. и превысил 7 млрд руб.

Проведенный автором анализ распространения практик инициативного бюджетирования и самообложения в субъектах РФ не позволил обнаружить устойчивой связи между типом региона (республика, область, край), его экономическим потенциалом, структурой доходов и его активностью при использовании инициативного бюджетирования и самообложения. 
Оба механизма имеют свои преимущества и недостатки. В частности, самообложение сопряжено с дополнительными расходами (затраты на организацию референдума могут быть соизмеримы с размером собранных средств), а инициативное бюджетирование может сопровождаться использованием схем «пожертвования в обмен на лояльность» в отношении предпринимателей, давлением на граждан в целях сбора необходимого минимума пожертвований, что дискредитирует саму сущность механизмов гражданской инициативы [Вагин и др., 2015].

Кроме того, как известно, одной из предпосылок формирования публичных финансов как экономической категории в ее современном понимании был переход к регулярному взиманию налогов в денежной форме. Исходя из этого, самообложение можно рассматривать как один из ранних этапов формирования доходов и финансирования расходов территориальных сообществ. Следовательно, рассматривать средства самообложения граждан как существенный (в потенциале) источник доходов местных бюджетов, сопоставимый с объемами регулярных налоговых поступлений, было бы некорректно. По нашему мнению, их роль может быть только вспомогательной, а основной задачей при использовании обеих указанных технологий является не решение бюджетных проблем, а вовлечение населения в процесс принятия бюджетных решений, предоставление условий для проявления гражданской активности.

\section{Целевые межбюджетные трансферты: иллюзия контроля и согласования интересов}

Учитывая значительные объемы межбюджетных трансфертов, очевидна необходимость самого пристального внимания к этой части доходов местных бюджетов. При этом нужно иметь в виду, что «организация и совершенствование межбюджетных отношений - не самоцель, а лишь средство для решения конкретных задач территориального развития» [Лексин, Швецов, 2007], и, исходя из этого тезиса, принимать решения об оптимизации структуры трансфертов.

Структура трансфертных перечислений состоит из дотаций на выравнивание бюджетной обеспеченности, целевых субсидий (предоставляемых на условиях софинансирования) и субвенций на осуществление переданных полномочий и программно-целевого 
финансирования. Но если величина дотаций в прошедшие 12 лет оставалась практически неизменной, то объемы субсидий выросли почти в пять раз, а субвенций - в три раза (рис. 3).

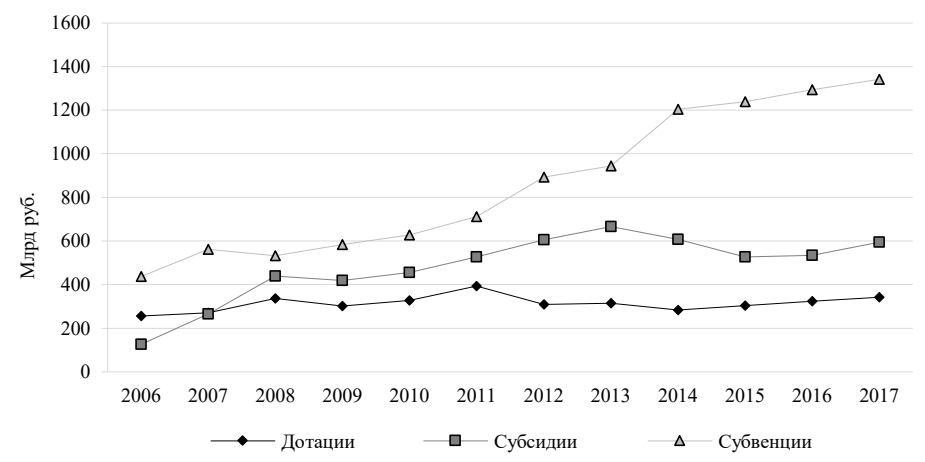

Puc. 3. Межбюджетные трансферты в местных бюджетах в 2006-2017 гг.

О чем свидетельствует эта тенденция? В первую очередь, о росте зависимости органов местного самоуправления от решений федеральных и региональных властей, а также о повсеместном внедрении программно-целевого бюджетирования.

Однако подход, при котором явно преобладают целевые трансферты, вызывает определенные сомнения. Так, например, ст. 9 Европейской Хартии местного самоуправления гласит, что «предоставление субсидий не должно наносить ущерба основополагающему принципу свободного выбора органами местного самоуправления политики в сфере их собственной компетенции». С этим тезисом трудно спорить. Объективно, местные власти больше заинтересованы в получении нецелевых средств (дотаций), которые позволяют им более гибко и своевременно реагировать на ситуацию в муниципальном образовании. Устоявшееся в управленческих кругах мнение о том, что целевые трансферты оказываются более эффективными, поскольку более «прозрачны» и лучше поддаются контролю, представляется не совсем верным. Возрастающее и избыточное использование целевых трансфертов порождает достаточно существенные проблемы. Рассмотрим их более подробно.

Так, избыточная передача на нижестоящий уровень государственных полномочий (о чем свидетельствует рост субвенций) 
приводит к снижению темпов развития территорий в связи с ростом неопределенности и несогласованности интересов сторон, разбалансировкой полномочий, ресурсов и ответственности за результаты [Левина, 2017].

Множество проблем порождает и сложившаяся в России практика формирования и распределения субсидий. Как правило, финансирование субсидий, выделяемых муниципальным образованиям в сфере ЖКХ, образовании, социальной политики и т.д., является многоканальным даже в рамках каждого из направлений расходов (несмотря на многократно озвученную необходимость перехода к более крупным «блочным» субсидиям). Это негативно влияет на согласование региональных и местных интересов при выборе приоритетных направлений социально-экономического развития. Множественность субсидий, а значит, их более конкретная и узкоцелевая направленность, как это ни парадоксально, не упрощает, а затрудняет контроль. И это не только российская проблема [Ки-мл., 2003]. Характеризуя ситуацию 1980-х годов в США, Н. Кейден отмечает: «...Бюджет на всех уровнях представляет собой сложный лабиринт межуровневых правительственных грантов, субсидий и компенсаций, нацеленных на различные цели и финансируемых в соответствии с различными критериями. Нелегко обнаружить, кем делаются определенные расходы, сколько и на какие цели... » [Кейден, 2003].

Отдельный пласт проблем связан с несвоевременным и некачественным планированием субсидий и задержками их перечисления. Это приводит к тому, что во многих субъектах Федерации на момент принятия закона о региональном бюджете остаются неизвестными ни объем предполагаемых поступлений, ни их распределение по получателям. Очевидно, что не зная этого, местные власти не могут планировать свои расходы. В таких условиях фактическая реализация идеи среднесрочного и долгосрочного бюджетного планирования для них становится невозможной.

Во многих субъектах Федерации в законе о бюджете субъекта РФ некоторые виды субсидий не распределяются по получателям до начала финансового года. Между тем их доля в муниципальных бюджетах может быть очень существенной. Например, в 2016 г., по данным Минфина России, в таких регионах, как Самарская область, Москва, Республика Ингушетия, Калининградская область, Республика Мордовия, Омская, Тамбовская 
области, Республика Бурятия, Ленинградская, Кировская области доля целевых трансфертов, предоставляемых местным бюджетам и распределяемых законом о бюджете субъекта РФ, в общем объеме целевых трансфертов составляла от 20 до 70\%, а еще в 12 регионах данный показатель достигал 70-80\%. Нормальной является ситуация, когда в законе о региональном бюджете все субсидии распределены по получателям.

Примечательно, что доля субсидий в общем объеме целевых трансфертов, предоставляемых местным бюджетам и распределяемых законом о бюджете субъекта РФ в общем объеме целевых трансфертов, не зависит от экономического развития региона и его налогового потенциала, а определяется особенностями бюджетного планирования и проводимой региональными властями политикой взаимодействия с муниципальными образованиями.

При этом объемы субсидий в течение финансового года очень часто подвергаются существенным корректировкам (обычно в сторону уменьшения), что опять же крайне негативно сказывается на эффективности применения программно-целевого бюджетирования на местном уровне.

Но даже если трансферты выделяются в полном объеме, их поступления могут быть неравномерно распределены во времени. Весьма распространена практика, когда целевые средства поступают получателю уже в конце финансового года, что порождает понятные сложности в их освоении и отрицательно влияет на эффективность их использования.

Таким образом, нарастание объемов целевых трансфертов негативно сказывается на возможности муниципалитетов по проведению собственной бюджетной политики, а иллюзия контроля за использованием средств оборачивается большими проблемами в части эффективности бюджетных расходов. На наш взгляд, все это свидетельствует о необходимости поиска баланса между целевыми и нецелевыми трансфертами, что в современных условиях неизбежно требует существенного расширения использования стимулирующих и выравнивающих дотаций муниципальным образованиям.

Отметим, что сформулированные выводы в большей степени применимы в отношении городских округов и муниципальных районов. К сожалению, усредненная оценка данных 
по муниципальным бюджетам позволяет сформировать лишь самое общее представление о современном состоянии местных финансов.

\section{Некоторые особенности финансов крупных городских округов и «малых» поселений}

Недавние изменения бюджетного законодательства в сфере местных финансов (федеральный закон «О внесении изменений в Бюджетный кодекс Российской Федерации» от 29.11.2014 № 383-Ф3) оказались довольно существенными в первую очередь для сельских поселений. Прежде всего для них был значительно (примерно в два раза по количеству) сокращен перечень вопросов местного значения, по сравнению с аналогичным перечнем для городских поселений, а затем - заметно «урезан» размер доходов (в частности, норматив зачислений НДФЛ, который является основным источником доходов местных бюджетов, был снижен для сельских поселений с 10 до 2\%). По нашему мнению, это не может рассматриваться как положительная тенденция в сфере местных финансов. Введение различных перечней вопросов местного значения для городских и сельских поселений не решило проблемы недостаточности средств, не привело к заметным улучшениям в области сбалансированности местных бюджетов.

При этом, по нашему мнению, рассматривая местные финансы, следует особо выделять бюджеты крупных и экономически развитых городских округов, с одной стороны, и малых поселений - с другой. Эти два «полюса» среди муниципальных образований имеют столь существенные различия, что усредненные рекомендации к ним мало применимы.

В бюджетах городских округов аккумулируется основной объем налоговых и неналоговых поступлений муниципального уровня, суммы дотаций в бюджетах городских округов несколько ниже, а целевых трансфертов - выше по сравнению с муниципальными образованиями других типов. Все это объясняется тем, что в группу городских округов входят административные центры субъектов РФ и крупные промышленные города с высокой численностью населения и адекватной налоговой базой (всего чуть более 100 городов). Именно они в основном являются самыми финансово стабильными (на общем фоне) муниципальными образованиями. Уровень 
налоговых и неналоговых доходов в расчете на одного жителя в них в несколько раз выше, чем в остальных муниципальных образованиях, и за счет этого структура доходов принципиально отличается от структуры других местных бюджетов, формирующихся преимущественно за счет трансфертов. Однако основная масса городских округов имеет низкий экономический потенциал и высокодотационные бюджеты. При этом отметим, что за счет межбюджетного выравнивания после распределения трансфертов уровень бюджетных доходов в расчете на одного жителя в муниципалитетах варьируется не столь сильно. Например, в Тульской области в последние годы данный показатель до распределения трансфертов отличается в пять и более раз, а после их распределения - в 1,5-2 раза.

Понятно, что интересы крупнейших городов в межбюджетном взаимодействии существенно отличаются от интересов остальных муниципальных образований. Для них предпочтительна передача большего объема налоговых доходов по дополнительным нормативам, неиспользование отрицательных трансфертов, применение стимулирующих механизмов в межбюджетном регулировании. Малые города в подавляющем большинстве проявляют больше склонности к патерналистской модели межбюджетных отношений.

Однако среди поселений в современной России преобладают сельские - их свыше 18 тыс., и это более чем в 10 раз превышает число городов. Так же, как и городские округа, сельские поселения существенно различаются по размерам и экономическому потенциалу. Около 300 из них имеют более 10000 жителей, около 80 насчитывают менее 100 чел. населения, но самую большую группу (свыше 8000) составляют поселения с количеством жителей менее 1000 человек.

Сельские поселения характеризуются множеством типичных особенностей и проблем, обусловленных как состоянием социально-экономической среды, так и качеством муниципального управления. Демографическая структура населения (преимущественно - пожилые), недостаточное количество рабочих мест и сложившийся относительно низкий уровень оплаты труда являются основными факторами, определяющими крайне низкие суммы налоговых доходов и значительную степень дотационности сельских бюджетов. В сложившейся системе распределения 
доходов между уровнями бюджетной системы сельские поселения не имеют реальной возможности самофинансирования. Для существенного увеличения налоговых поступлений у них также нет объективных возможностей, поэтому в качестве наиболее доступного механизма балансировки своего бюджета можно рекомендовать им активнее использовать экономическое межмуниципальное сотрудничество для оптимизации расходов. Межмуниципальная хозяйственная кооперация пока не получила значительного распространения, в 2016 г. в ней участвовали только 2\% муниципальных образований. Но на наш взгляд, данный механизм решения вопросов местного значения имеет значительный потенциал [Левина, 2016].

В целом местные финансы отражают положение института местного самоуправления в современной России. Для них характерно формальное использование современных практик и технологий бюджетного процесса, отсутствие необходимого влияния целевых трансфертов, сопровождающееся сохранением многолетней финансовой зависимости местных властей, что препятствует росту собственных доходов и повышению качества решения вопросов местного значения.

Для изменения сложившейся ситуации необходима модернизация механизма бюджетно-налоговых взаимодействий в регионах, который ныне выстроен по принципу «сверху-вниз», носит дискриминационный в отношении местного самоуправления характер и лишает муниципальные образования стимулов к инициативному развитию, и переход к организации бюджетного процесса на основе согласования финансовых интересов регионов и муниципальных образований, открывающего новые возможности для более полного раскрытия потенциалов их развития. В данном контексте финансовое регулирование в регионах предлагается рассматривать не как «субъект-объектное» взаимодействие, а как «субъект-субъектное».

Реализация данных положений на практике потребует внесения принципиальных изменений в федеральное бюджетное законодательство, ориентированных на расширение доходных источников местных властей, внедрение действенных стимулирующих механизмов в систему межбюджетного регулирования, 
изменение практики распределения целевых трансфертов как основного вида финансовой помощи территориям.

\section{Литература}

Вагин В. В., Гаврилова Н. В., Шаповалова Н. А. Инициативное бюджетирование: международный контекст российской версии // Научно-исследовательский финансовый институт. Финансовый журнал. 2015. № 3 (25). С. 117-122.

Величко A. B. «Бюджет для граждан» в Оренбургской области // Финансы. 2015. № 3. C. 20-21.

Дженсен М.К., Меклинг У.Х. Теория фирмы: поведение менеджеров, агентские издержки и структура собственности // Вестник С.-Петербургского ун-та. Серия Менеджмент. 2004. № 4. С. 118-191.

Жукова С. С., Зубкова Л.Д., Толчеева А. А., Дубиова Д. В. Бюджет для граждан как инструмент информирования населения (на примере Тюменской области) // Регион: системы, экономика, управление. 2014. № 4 (27). С. $138-145$;

Кейден Н. Государственное бюджетирование в неопределенной и нестабильной среде // Классики теории государственного управления: американская школа. М.: Изд-во МГУ, 2003. С. 536-552.

Ки-мл. В.О. Отсутствие теории бюджетирования // Классики теории государственного управления: американская школа. М.: Изд-во МГУ, 2003. C. $142-148$.

Левина В.В. Управление сбалансированностью бюджетов муниципальных образований // Финансы. 2016. № 1. С. 23-29.

Левина В.В. Межбюджетные трансферты и социально-экономическое развитие муниципальных образований // Финансы. - 2017. - № 5. - С. 18-24.

Лексин В.Н., Швецов А.Н. Государство и регионы: теория и практика государственного регулирования территориального развития. М.: Изд-во ЛКИ, 2007. -368 c.

Леонов С.Н. Бюджетные стимулы регионального развития // Известия Байкальского государственного университета. 2016. Т. 26. № 5. С. 723-730.

Леонов С.Н. Проблемные результаты и перспективы реформы местного самоуправления в России // Пространственная экономика. 2017. № 3 (51). C. $107-132$.

Норт Д. К. Институты, институциональные изменения и функционирование экономики. - М.: Фонд экономической книги «Начала», 1997. 180 с.

Силуанов А.Г. Тучные годы остались в прошлом, сегодня нам нужно повышать качество работы с расходами // Финансы. 2014. № 1. С. 3-5.

Статья поступила 25.05.2018.

\section{Summary}

Vera V. Levina, Tula State University, Tula, Russia

Local Finances in the New Situation

$\mathrm{He}$ article is given the analyses of the legal framework and practice of forming and using budget funds at the local level. According to the author, in Russia the potential of local finance is not used in full, which is due to the existence of stable 
stereotypes in the field of municipal budgetary policy related to the use of program budgeting, an increase in the level of budget transparency, the stability of budget revenues, the use of financial mechanisms for involving citizens in solution of local issues. In order to find out how effective the use of these budget mechanisms is, to reveal not always obvious consequences of improvements in the budget process, the author analyzes the real state of affairs in the field of local finance, focusing on changes in the municipal budget policy of recent years.

Municipal finance; budget policy; performance budgeting; budget revenues; interbudgetary transfers

\section{References}

Vagin V. V., Gavrilova N.V., Shapovalova N.A. (2015) Iniciativnoe byudzhetirovanie: mezhdunarodnyj kontekst rossijskoj versii. Nauchnoissledovatel'skij finansovyj institut. [Financial Journal]. No. 3 (25). Pp. 117-122. (In Russ.)

Velichko A. V. (2015) "Byudzhet dlya grazhdan” v Orenburgskoj oblasti. [Finance]. No. 3. Pp. 20-21. (In Russ.)

Dzhensen M.K., Mekling U.H. (2004) Teoriya firmy: povedenie menedzherov, agentskie izderzhki i struktura sobstvennosti. [Vestnik of Saint Petersburg University. Management]. No. 4. Pp. 118-191. (In Russ.)

Zhukova S.S., Zubkova L. D., Tolcheeva A.A., Dubcova D. V. (2014) Byudzhet dlya grazhdan kak instrument informirovaniya naseleniya (na primere Tyumenskoj oblasti). [Region: Systems, Economics, Management]. No. 4 (27). Pp. 138-145. (In Russ.)

Kejden N. (2003) Gosudarstvennoe byudzhetirovanie v neopredelennoj i nestabil'noj srede. Klassiki teorii gosudarstvennogo upravleniya: amerikanskaya shkola. Moscow. MGU Publ. Pp. 536-552. (In Russ.)

Ki-ml. V.O. (2003) Otsutstvie teorii byudzhetirovaniya. Klassiki teorii gosudarstvennogo upravleniya: amerikanskaya shkola. Moscow. MGU Publ. Pp. 142-148. (In Russ.)

Levina V. V. Upravlenie sbalansirovannost'yu byudzhetov municipal'nyh obrazovanij. [Finance]. 2016. No. 1. Pp. 23-29. (In Russ.)

Levina V.V. (2017) Mezhbyudzhetnye transferty i social'no-ehkonomicheskoe razvitie municipal'nyh obrazovanij. [Finance]. No. 5. Pp. 18-24. (In Russ.)

Leksin V.N., Shvecov A.N. (2007) Gosudarstvo i regiony: teoriya i praktika gosudarstvennogo regulirovaniya territorial'nogo razvitiya. Moscow. LKI Publ. 368 p. (In Russ.)

Leonov S.N. (2016) Byudzhetnye stimuly regional'nogo razvitiya. [Bulletin of Baikal State University]. T. 26. No. 5. Pp. 723-730. (In Russ.)

Leonov S.N. (2017) Problemnye rezul'taty i perspektivy reformy mestnogo samoupravleniya v Rossii. [Spatial Economics]. No. 3 (51). Pp. 107-132. (In Russ.)

Nort D.K. (1997) Instituty, institucional'nye izmeneniya i funkcionirovanie ehkonomiki. Moscow. Fond ehkonomicheskoj knigi «Nachala». 180 p. (In Russ.)

Siluanov A. G. (2014) Tuchnye gody ostalis' v proshlom, segodnya nam nuzhno povyshat' kachestvo raboty s raskhodami. [Finance]. No. 1. Pp. 3-5. (In Russ.). 